\title{
Multiple Intracerebral Hemorrhages Prior to the Diagnosis of Acute Lymphocytic Leukemia
}

Yu Kinoshita ${ }^{1 *}$, Hidekazu Horiuchi², Naoki Kato' ${ }^{1}$ and Ching-Chan Su${ }^{1}$

${ }^{1}$ Department of Neurosurgery, Yamagata Prefectural Shinjo Hospital, Japan

2Internal Medicine, Yamagata Prefectural Shinjo Hospital, Japan

\begin{abstract}
Intracerebral Hemorrhage $(\mathrm{ICH})$ can be seen in patients with acute leukemia, however, it is extremely rare to present $\mathrm{ICH}$ as the initial presentation in previously undiagnosed acute leukemia. Only four cases were reported in the English literature.

This 17-year-old male was admitted with sudden onset of headache, nausea and vomiting. Three days before this admission, he visited an ophthalmological department for bilateral blurred vision. Bilateral retinal hemorrhages were detected by the funduscopic examination; however, further examinations were not performed at that time. On arrival at our hospital, his Glasgow Coma Scale was 8 (E2, V3, M3) and urgent head CT scan showed multiple Computed Tomography (CT) head demonstrated multiple ICHs. On admission, his White Blood Cell (WBC) count was $584,000 / \mu \mathrm{l}$ with evidence of blast crisis, and platelet count was $18,000 / \mu \mathrm{l}$. Despite urgent platelet and plasma transfusions, his conscious level deteriorated, and the patient died 12 hours after the admission due to respiratory failure.
\end{abstract}

The importance of correct diagnosis and early management of leukemia is emphasized, which may prevent blast crisis and disseminated intravascular coagulation leading to fatal $\mathrm{ICH}$.

Keywords: Acute leukemia; Blast crisis; Bleeding tendency; Coagulopathy; Intracerebral hemorrhage

\section{Introduction}

Intracerebral Hemorrhage (ICH) is one of the most catastrophic complications in acute leukaemia [1,2]. However, it is extremely rare to encounter $\mathrm{ICH}$ as the initial presentation of previously undiagnosed acute leukemia. To our knowledge, only 4 cases have been reported [36 . We present a case of multiple ICHs prior to the diagnosis of acute leukemia.

\section{Case Presentation}

A 17-year-old male was transferred to our emergency department with chief complaints of severe headache, vomiting, and acute onset of unconsciousness. Past medical history and family history were both nil of note, however, 3 days before the admission, he visited an ophthalmologist for bilateral blurred vision. Bilateral retinal hemorrhage was found in funduscopic examination, and he was referred to a University hospital for further investigation, any other examinations were not performed at that time. On arrival, he became comatose, and multiple ICHs were detected on an urgent head computed tomography (CT) (Figure 1). His white blood cell (WBC) count was $584,000 / \mu \mathrm{l}$ demonstrating blast crisis, and platelet count was $18,000 / \mu l$. Peripheral blood smear and flow cytometry confirmed the diagnosis of T-cell type acute lymphocytic leukemia. The hepatic and renal functions were within a normal range. There was no apparent evidence of bruise, petechiae, or internal hemorrhage. Despite urgent platelet and plasma transfusions, he did not response to our treatment. Subsequently he suffered from respiratory failure and died 12 hours after the admission. Postmortem chromosomal analysis demonstrated chromosome $6 \mathrm{p}$ loss.

\section{Discussion}

ICH associated with leukemia may arise from a wide range of various factors, such as vessel wall lesions, leukemic cell invasion, low platelet count, platelet dysfunction, liver damage with the delayed synthesis of coagulation factors, increased plasmin- or elastase-

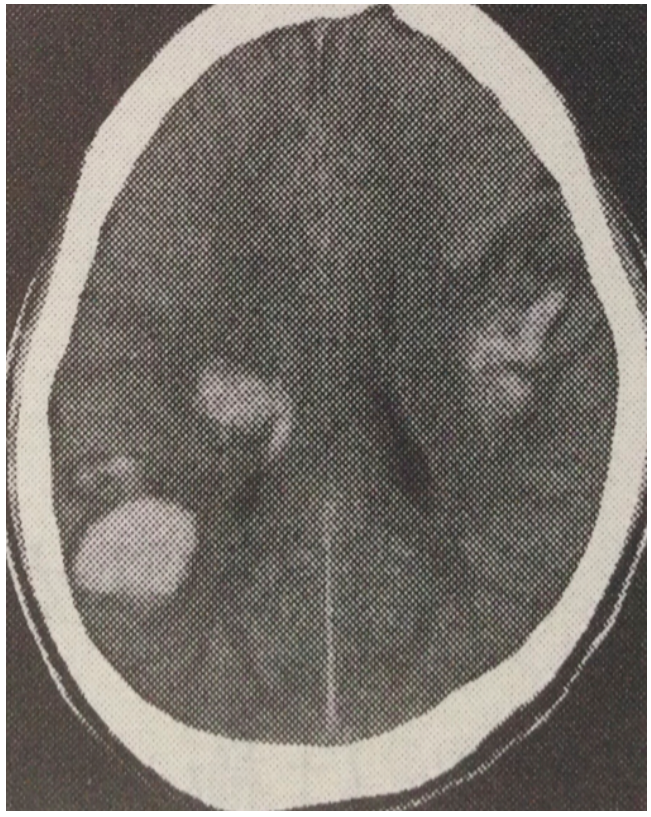

Figure 1: Multiple intracerebral hematomas in right parietal lobe, periventricle and left frontal lobe.

*Corresponding author: Yu Kinoshita, Department of Neurosurgery, Yamagata Prefectural Shinjo Hospital, 12-55 Wakabacho, Shinjo-City, Yamagata, Japan, Tel: +81-2-3322-5525; Fax: +81-2-3322-5525; E-mail: yu1129@hotmail.co.jp

Received November 17, 2014; Accepted November 25, 2014; Published November 26, 2014

Citation: Kinoshita Y, Horiuchi H, Kato N, Su CC (2014) Multiple Intracerebral Hemorrhages Prior to the Diagnosis of Acute Lymphocytic Leukemia. J Clin Case Rep 4: 453. doi:10.4172/2165-7920.1000453

Copyright: (c) 2014 Kinoshita Y, et al. This is an open-access article distributed under the terms of the Creative Commons Attribution License, which permits unrestricted use, distribution, and reproduction in any medium, provided the original author and source are credited. 
Citation: Kinoshita Y, Horiuchi H, Kato N, Su CC (2014) Multiple Intracerebral Hemorrhages Prior to the Diagnosis of Acute Lymphocytic Leukemia. J Clin Case Rep 4: 453. doi:10.4172/2165-7920.1000453

Page 2 of 2

\begin{tabular}{|c|c|c|c|c|c|c|}
\hline & Gender & Age (years) & $\mathrm{ICH}$ & Platlets $(/ \mu \mathrm{l})$ & WBC $(/ \mu \mathrm{l})$ & outcome \\
\hline Chung, et al. [3] & $\mathrm{F}$ & 24 & multiple & 10,000 & 12,700 & survived \\
\hline Kawakami, et al. [4] & $\mathrm{F}$ & 14 & multiple & 14,000 & 128,500 & survived \\
\hline Naunheim, et al. [5] & $M$ & 55 & single & 30,000 & 92,000 & survived \\
\hline Shiber, et al. [6] & $M$ & 19 & multiple & 30,000 & $1,210,000$ & dead \\
\hline Present Case & $M$ & 17 & multiple & 18,000 & 584,000 & dead \\
\hline
\end{tabular}

M: Male; F: Female; ICH: Intracerebral Haemorrhage; WBC: White Blood Cell

Table 1: Characteristics undiagnosed patients whose initial manifestation were $\mathrm{ICH}$.

induced fibrinolysis, Disseminated Intravascular Coagulation (DIC), anticoagulant therapy, hyperleukocytosis, hypoxia, and sepsis [1-3,7-9] ICH secondary to acute leukemia accounts for approximately $20 \%$ of mortality despite recent improvement of chemotherapeutic regimens, targeted pharmacotherapy, and close monitoring of associated coagulation abnormalities [7,8]. Surgical intervention has little role in the management of ICH with coagulopathy such as leukemic blast crisis [2]. Four previous cases of ICH as the initial presentation in undiagnosed leukemic patients were studied particularly on the clinical manifestations, management, and pathogenesis (Table 1). Surgical intervention was not performed in all of the previously reported cases. The median age of the reported cases is 25.8 (range, 14-55) years old, and male female ratio is $3: 2$. The average platelet count is $24,000 / \mu \mathrm{l}$ (range $10,000-30,000 / \mu \mathrm{l}$ ) and the average WBC count is $405,440 / \mu \mathrm{l}$ (range 12,700-1,210,000/ $\mathrm{ll}$ ). Three patients were successfully treated with conservative intervention correction of coagulopathy. Chern et al. insists that leukemia patients with ICH should be managed with platelet transfusions until the platelet level exceeds 50,000/ $\mu$ l. On average, Chern's group transfused 16 units of platelet within the first 36 hours of ICH [2]. In our case, although we transfused 10 units of platelet soon after the admission, he did not respond to the intervention and died without any clinical improvement. Thus initiation of chemotherapy regimen could not be performed.

Our patient visited an ophthalmologist with a chief complaint of bilateral blurred visions 3 days before the onset of conscious disturbance. Bilateral localized retinal hemorrhages were observed, however, further examinations were not performed at that time. Abnormal fundal hemorrhage in young adults should be investigated further for hematological disorders such as leukemia, Hodgkin and non-Hodgkin lymphoma, myeloproliferative and myelodysplastic syndrome as well as coagulopathies [10]. Although it is extremely difficult to determine outcome of the patient, prompt appropriate investigation might have lead to earlier and correct diagnosis. Furthermore, this might have influenced outcome of this patient. We would like to emphasize not only the importance of prompt and appropriate investigation, but also the importance of expanding horizons in natural history of acute lymphocytic leukemia.

\section{Conclusion}

ICH as the initial presentation of acute leukemia can lead to high mortality. Our case suggests that correct and urgent diagnosis is crucial in management of ICH with acute leukemia.

\section{Disclosure}

We have no financial support and industry affiliations. We don't have any personal or institutional financial interest in drugs, materials, or devices described in our submissions.

\section{Acknowledgment}

We thank Dr. Katsushi Tajima for his hematological insight to this case and Dr. Maki Jitsumura for English proofreading.

\section{References}

1. Chen CY, Tai CH, Tsay W, Chen PY, Tien HF (2009) Prediction of fatal intracranial hemorrhage in patients with acute myeloid leukemia. Ann Oncol 20: $1100-1104$

2. Chern JJ, Tsung AJ, Humphries W, Sawaya R, Lang FF (2011) Clinical outcome of leukemia patients with intracranial hemorrhage. Clinical article. J Neurosurg 115: 268-272.

3. Chung C, Hsu NC, Horng H, Chang CS (2003) Successful treatment for multiple cerebral hemorrhage in a newly diagnosed patient with acute promyelocytic leukemia. Leuk Lymphoma 44: 1059-1061.

4. Kawakami C, Inoue A, Takitani K, Yuki M, Tamai H (2010) Successful treatment of acute monocytic leukemia with intracranial hemorrhage as the first manifestation. Pediatr Int 52: e218-220.

5. Naunheim MR, Nahed BV, Walcott BP, Kahle KT, Soupir CP, et al. (2010) Diagnosis of acute lymphoblastic leukemia from intracerebral hemorrhage and blast crisis. A case report and review of the literature. Clin Neurol Neurosurg 112: $575-577$.

6. Shiber JR, Fines RE (2011) Cerebral hemorrhage due to hyperleukocytosis. J Emerg Med 40: 674-677.

7. Dayyani F, Mougalian SS, Naqvi K, Shan J, Ravandi F, et al. (2011) Prediction model for mortality after intracranial hemorrhage in patients with leukemia. Am J Hematol 86: 546-549.

8. Kim H, Lee JH, Choi SJ, Kim WK, Lee JS, et al. (2004) Analysis of fatal intracranial hemorrhage in 792 acute leukemia patients. Haematologica 89: 622-624.

9. Kim H, Lee JH, Choi SJ, Lee JH, Seol M, et al. (2006) Risk score model for fatal intracranial hemorrhage in acute leukemia. Leukemia 20: 770-776.

10. Shalchi Z, Taylor SR, Lightman S (2011) The eye in haematological disease. $\mathrm{Br}$ J Hosp Med (Lond) 72: 691-697. 